\title{
Do heart rate variability is relationed to endurance performance in female futsal players?
}

\section{A variabilidade da frequência cardíaca está relacionada ao desempenho de resistência em jogadoras de futsal?}

\author{
Julio Cesar Barbosa de Lima Pinto ${ }^{1,2}$ \\ (D) https://orcid.org/0000-0002-2066-4408 \\ Radamés Maciel Vitor Medeiros ${ }^{3}$ \\ (D) https://orcid.org/0000-0003-0811-2851 \\ Arnaldo Luis Mortatti ${ }^{4}$ \\ (D) https://orcid.org/0000-0001-6743-0070 \\ Fábio Yuzo Nakamura ${ }^{5,6,7}$ \\ (D) https://orcid.org/0000-0002-5336-3652 \\ Leonardo de Sousa Fortes ${ }^{5}$ \\ (D) https://orcid.org/0000-0002-0778-769X \\ Daniel Gomes da Silva Machado ${ }^{4}$ \\ (D) https://orcid.org/0000-0002-8426-0488 \\ André Igor Fonteles ${ }^{8}$ \\ (D) https://orcid.org/0000-0003-1095-7845
}

Abstract - The study aimed to verify the correlation between resting heart rate variability $\left(\mathrm{HRV}_{\text {rest }}\right)$ and endurance performance in female futsal players, as well as to evaluate the reliability of this parasympathetic autonomic marker. A total of 16 female futsal players (age: $22 \pm 3$ years; $\mathrm{VO}_{2}$ max: $42.3 \pm 2.0 \mathrm{ml} \cdot \mathrm{kg}^{-1} \cdot \mathrm{min}^{-1}$ ) were evaluated during the first week of preseason training. Vagal modulation was evaluated from the $\mathrm{HRV}_{\text {rest }}$ (i.e., log-transformed root mean square of successive R-R interval differences - Ln-RMSSD) for two consecutive days, while endurance performance was evaluated by the Yo-Yo Intermittent Recovery Test, Level 1 (Yo-Yo IR1). Pearson correlation was used to analyze the relationship between the variables. Strong correlation between the $H R V_{\text {rest }}$ index and endurance performance $(r=0.643 ; p=0.007)$. Reliability was tested through the intraclass correlation coefficient, coefficient of variation $(\mathrm{CV})$, and Bland-Altman analysis of the agreement. Furthermore, acceptable repeatability of $\mathrm{HRV}_{\text {rest }}$, but with great inter-subject variability ( $\mathrm{ICC}=0.670,95 \% \mathrm{CI}=0.056-0.885, \mathrm{CV}=15.8 \%)$. The current study demonstrated a strong correlation between Ln-RMSSD and endurance performance, and despite the acceptable values of intrasubject reliability, $\mathrm{HRV}_{\text {rest }}$ presented high inter-individual variability in female futsal players. Key words: Autonomic nervous system; Team sport; Sport performance.

Resumo - O objetivo do estudo foi verificar a correlação entre a variabilidade da frequência cardiaca de repouso $\left(V F C_{\text {Repouss }}\right.$ ) e o desempenho de resistência em jogadoras de futsal, bem como avaliar a confiabilidade do marcador parassimpático. No total, 16 jogadoras de futsal (idade: $22 \pm 3$ anos; $\mathrm{VO}_{2}$ max: $\left.42.3 \pm 2.0 \mathrm{ml} . \mathrm{kg}^{-1} \cdot \mathrm{min}^{-1}\right)$ foram avaliadas durante a primeira semana de treinamento da pré-temporada. A modulação vagal foi avaliada a partir da VFC de repouso (isto é, raiz quadrada da média das diferenças sucessivas ao quadrado dos intervalos $R-R$ adjacentes - Ln-RMSSD) por dois dias consecutivos, enquanto o desempenho da resistência foi avaliado pelo Yo-Yo Intermittent Recovery Test, Level 1 (Yo-Yo IR1). A correlação de Pearson foi utilizada para analisar a relação entre as variáveis. A confiabilidade foi testada através do coeficiente de correlação intraclasse, coeficiente de variação e análise de concordância de Bland-Altman. Observou-se uma forte correlação entre o indice de $V F C_{\text {repouso }}$ eo desempenho de endurance $(r=0,643 ; p=0,007)$. Por outro lado, repetibilidade aceitável dos indices de repouso vagal, mas com grande variabilidade interindividual (ICC =0,670, $I C=0,056-0,885, C V=15,8 \%)$. O presente estudo apresentou forte correlação entre Ln-RMSSD e desempenho de endurance, e mesmo com valores aceitáveis de confiabilidade intrasujeito, a VFC em repouso apresentou alta variabilidade interindividual em jogadoras de futsal.

Palavras-chave: Sistema nervoso autônomo; Esportes coletivos; Desempenho esportivo.
1 Federal University of Ceará. Faculty of Medicine. Fortaleza, CE. Brazil. 2 Faculty Terra Nordeste. Caucaia, CE. Brazil. 3 University Center of Rio Grande do Norte. Natal, RN. Brazil. 4 Federal University of Rio Grande do Norte. Department of Physical Education. Natal, RN. Brazil. 5 Federal University of Paraíba. Department of Physical, João Pessoa. PB, Brazil.

6 James Cook University, The College of Healthcare Sciences. Townsville, Australia.

7 "G. d'Annunzio" University of ChietiPescara, Department of Medicine and Aging Sciences. Chieti, Italy. 8 Federal Institute of Education, Science and Technology. Itapipoca, CE. Brazil.

Received: May 11, 2020

Accepted: March 25, 2021

How to cite this article Pinto JCBL, Medeiros RMV, Mortatti AL, Nakamura FY, Fortes LS, Machado DGS, Fonteles AI. Do heart rate variability is relationed to endurance performance in female futsal players? Rev Bras Cineantropom Desempenho Hum 2021, 23:e73799. D0I: http://doi. org/10.1590/1980-0037.2021v23e73799

Corresponding author Julio Cesar Barbosa de Lima Pinto Faculty of Medicine, Federal University of Ceará

Rua Monsenhor Furtado, s/n, 60430-350, Rodolfo Teófilo, Fortaleza (CE), Brasil

E-mail: julioduibmx@gmail.com

Copyright: This work is licensed under a Creative Commons Attribution 4.0 International License. 


\section{INTRODUCTION}

Futsal is an intermittent sport that involves high-intensity activities, such as accelerations, decelerations, and changes of direction, mobilizing the aerobic and anaerobic energetic systems ${ }^{1}$. Monitoring fitness changes in futsal players provides valuable information on physical and physiological adaptations to training ${ }^{2}$. There seems to be a relationship between external training load and physiological adaptations in athletes ${ }^{2,3}$. Physiological adaptations have also been monitored through autonomic nervous system (ANS) responses, analyzed from heart rate variability (HRV), which can provide useful information regarding changes in training status ${ }^{3}$. HRV is sensitive to changes in training loads ${ }^{4}$. Buchheit recently suggested that HRV indices, used as an indicator of the athletes' training status, may be more sensitive to changes in training loads ${ }^{3}$. HRV has been commonly used to monitor training adaptations in futsal players ${ }^{5}$. Monitoring individual $\mathrm{HRV}$ responses is suggested since large inter-individual variations may exist in response to futsal training ${ }^{6}$ and monitoring fitness changes of futsal players provides valuable information about the physical and physiological adaptations to training ${ }^{2}$.

Increases in vagal-related indices of $H R V$ are evident when positive adaptation to training has occurred, allowing for increases in performance ${ }^{7}$. Resting vagalrelated HRV indices that are related to cardiorespiratory fitness ${ }^{8}$ and a decrease in HRV is often reported with detraining or increased fatigue ${ }^{9}$. HRV indices may reflect positive changes in high-intensity intermittent activity in futsal players. This concomitant improvement may provide an important and simple monitoring tool for training optimization in futsal and other team sports, avoiding the need for frequent maximal testing and HRV indices may assist with the identification of individual training adaptations and/or early signs of maladaption ${ }^{5}$.

In this regard, the natural square root logarithmic transformation of the mean of successive differences in adjacent RR intervals (Ln-RMSSD) has been deemed the most appropriate HRV index for assessing the relationship between the ANS and sport performance ${ }^{9}$. Athletes with high Ln-RMSSD are expected to experience less perturbation of the ANS in response to stress imposed by external training loads, suggesting that improving vagal-related HRV can be beneficial for sports performance enhancement ${ }^{6}$. In acute conditions, Ln-RMSSD values and wellness responses may be useful for preventing the accumulation of fatigue in female soccer players ${ }^{10}$, indicating that resting LnRMSSD may be a simple and sensitive indicator to monitor changes in physical fitness during training ${ }^{3,7}$. Additionally, peak oxygen uptake $\left(\mathrm{VO}_{2 \text { peak }}\right)$ and running velocity increased significantly during HRV guided training but not during predefined standard training, which may partly explain the differences in the change in maximal running performance ${ }^{11}$, as well as Ln-RMSSD values, was inversely associated with maximal aerobic speed ${ }^{12}$.

Changes in HRV have been associated with positive adaptations to training (i.e., assessing and predicting the impact of aerobic training on endurance running performance ${ }^{13}$, improved measures of both peripheral and central (aerobic) work capacities ${ }^{14}$, athletic achievements in recreational long-distance runners $\left.{ }^{14}\right)$. Thereby, the HRV appears to be an appropriate tool to monitor the effects of physical training loads on performance and fitness and could eventually be used to prevent overtraining states ${ }^{15}$. Overtraining state seemed to be related to the tendency of HRV to decrease in the standing position as a sign of pronounced vagal withdrawal and sympathetic activation, meanwhile, in some cases, may cause decreased sympathetic excitability ${ }^{15}$, increased HRV, 
particularly in the vagal range, together with a reduced resting heart rate suggests a cardiac autonomic imbalance with extensive parasympathetic modulation in this athlete when overtrained ${ }^{16}$.

There is a strong correlation between parasympathetic indices of HRV (analyzed before the training) with the performance improvement in Yo-Yo IR1 in football athletes during pre-season ${ }^{17}$. A recent meta-analysis showed that a positive adaptation to training leading to enhancement of athletic performance is generally associated with an increase in the resting cardiac vagal activity ${ }^{7}$. Besides, a greater increase in Ln-RMSSD in the preparatory training was positively related to the increase in aerobic fitness of futsal players, and, hence, HRV has been used as a practical tool for planning and adjusting training programs ${ }^{18}$. The Yo-Yo IR tests provide a simple and valid way to obtain important information of an individual's capacity to perform repeated intense exercise and to examine changes in performance ${ }^{19}$. Aerobic endurance to be an important quality for the competitive level in futsal, it seems important to improve the cardiovascular capacity of futsal players ${ }^{1}$. The use of low-cost, easy-to-apply, and non-invasive instruments to identify the state of training (e.g., Ln-RMSSD) and specific physical capacity (e.g., total distance covered in Yo-Yo IR1) at the beginning of the season is essential to guide training in this sport.

The Ln-RMSSD index has been one of the most reliable cardiac autonomic control markers in athletes ${ }^{20}$. However, HRV reliability in female futsal athletes under a typical training condition is poorly known. The use of measures with low reliability would not identify the influence of a longitudinal intervention if the measurement error were larger than the expected change ${ }^{21}$. This knowledge is essential, considering that the level of HRV reliability in sport may determine its capacity to generate accurate information for coaches and sports physiologists ${ }^{22}$. Therefore, the present study aimed to analyze the relationship between a parasympathetic marker of HRV (i.e., Ln-RMSSD) and endurance performance in female futsal players. Also, the HRV reliability level was analyzed to demonstrate its utility for monitoring physiological adaptations in female players with similar characteristics. It was hypothesized that there would be a positive linear correlation between the endurance performance and Ln-RMSSD and that HRV would be a reproducible measure and demonstrate usefulness for application in female futsal players.

\section{METHODS}

\section{Participants}

Sixteen female futsal players participated in the study $(22 \pm 3$ years, $59.9 \pm$ $\left.7.03 \mathrm{~kg}, 161.2 \pm 5.86 \mathrm{~cm} ; 23.9 \pm 2.80 \mathrm{~kg} \cdot \mathrm{m}^{-2} ; 42.3 \pm 2.0 \mathrm{ml} \cdot \mathrm{kg}^{-1} \cdot \mathrm{min}^{-1}\right)$. The players had training volume 6-8 hours per week and participated in the main State, Regional and National competitions. Players with at least one year of practice and without injuries in the last six months were included. Goalkeepers and players who did not complete the injury investigation procedures or refused to participate in the study were excluded. The research protocol was carried out following the ethical principles contained in the Declaration of Helsinki and the guidelines proposed in Resolution 466/2012 of the National Health Council of Brazil on research involving human subjects. The study was approved by the Research Ethics Committee of the local University, under protocol 1.706.413. 


\section{Procedures}

Players were assessed, under conditions of equal environmental temperature, on two consecutive days in the pre-season training period, specifically on the second and third days of the first microcycle of the season. On both days, the HRV evaluation occurred in the morning, just after the awakening of each volunteer $(\sim 8: 30 \mathrm{~h})$, fasting, without caffeine or alcohol consumption. The two measures were used as a reference for the statistical analysis of the reliability of the evaluation method and the latter measure was utilized for further analysis with the total distance covered in Yo-Yo IR1. All the players evaluated were in the same training period, that is, returning from vacations and starting training. The first day of assessment was performed in the afternoon, corresponding only to the assessment of body composition and explanation of the procedures of this study. On the second day, the players performed the intermittent field performance test (Yo-Yo IR1).

\section{Heart rate variability}

The R-R intervals were continuously recorded for $10 \mathrm{~min}$ (rest condition) in the dorsal decubitus position with spontaneous respiratory rate and eyes $\operatorname{closed}^{23}$. The data acquisition was performed on two consecutive days, using a heart rate monitor (POLAR ${ }^{\oplus}$, model RS800 - Kempele, Finland). This equipment has been previously validated for this type of analysis ${ }^{24}$. For HRV analysis, only the 5 minutes with the greatest stationarity of the entire recording were considered ${ }^{25}$. The visual inspection and selection of the sections were performed in a doubleblind fashion. Ectopic beats (deviation greater than $20 \%$ of the adjacent R-R intervals) were identified and manually interpolated by the average of adjacent $\mathrm{R}-\mathrm{R}$ intervals. The time-domain parameters were calculated from the natural logarithm of the RMSSD. The analyzes were performed using the Kubios HRV program (University of Eastern Finland). The Ln-RMSSD values were presented in milliseconds (ms).

\section{Endurance performance}

The Yo-Yo IR1 was used to determine the endurance performance ${ }^{19}$. The test consists of performing two turns in a distance of 20 meters, with 10 seconds of active recovery between runs. Speed progression in stages is determined by the test-specific sound signal. For this, the route to be covered was marked with signaling cones, as well as the area destined for active recovery. The test ended when the athlete quitted or when she was unable to keep up with the pace determined by the test, committing two errors on the same stage. The total distance covered during the test was considered for endurance performance analysis. For the estimate $\mathrm{VO}_{2 \text { peak }}$ was used: distance $(m) \times 0.0084+36.4$, according to Bangsbo et al. ${ }^{19}$.

\section{Statistical analysis}

Data are presented as mean and standard deviation. The normality of the data was tested by the Shapiro-Wilk test, and the data of the vagal marker RMSSD were transformed into a natural logarithm (Ln-RMSSD). The intraclass correlation coefficient (ICC), associated with the 95\% confidence interval 
(95\% CI), and the Bland-Altman method were used to verify HRV reliability and agreement, respectively ${ }^{26}$. The relative reliability of the two measurements was analyzed using the ICC, which was interpreted as follows: $<0.30$ (small), 0.31-0.49 (moderate), 0.50 - 0.69 (large), 0.70 - 0.89 (very large), and 0.90 1.00 (near perfect) ${ }^{27}$. The coefficient of variation $(\mathrm{CV})$ tested the absolute variability between the two evaluations. The Pearson correlation coefficient was used to correlate the Ln-RMSSD of the second day and the endurance performance. The magnitudes of the correlation coefficient considered in the study were: uncorrelated $(\mathrm{r}<0.1)$, weak $(0.1<\mathrm{r}<0.3)$, moderate $(0.3<\mathrm{r}<$ $0.5)$, strong $(0.5<r<0.7)$, very strong $(0.7<r<0.9)$, almost perfect $(r>0.9)$, and perfect $(\mathrm{r}=1.0)$, according to Hopkins's definitions ${ }^{28}$. For all analyzes, the level of significance was set at 5\%. Statistical analyzes were performed using the Statistical Package for the Social Sciences - SPSS for Windows version 19.0 (SPSS, Chicago, IL, USA).

\section{RESULTS}

A significant strong positive correlation $(\mathrm{r}=0.643 ; \mathrm{p}=0.007$; Figure 1$)$ was observed between the Ln-RMSSD and endurance performance $(712 \pm 247.5 \mathrm{~m})$.

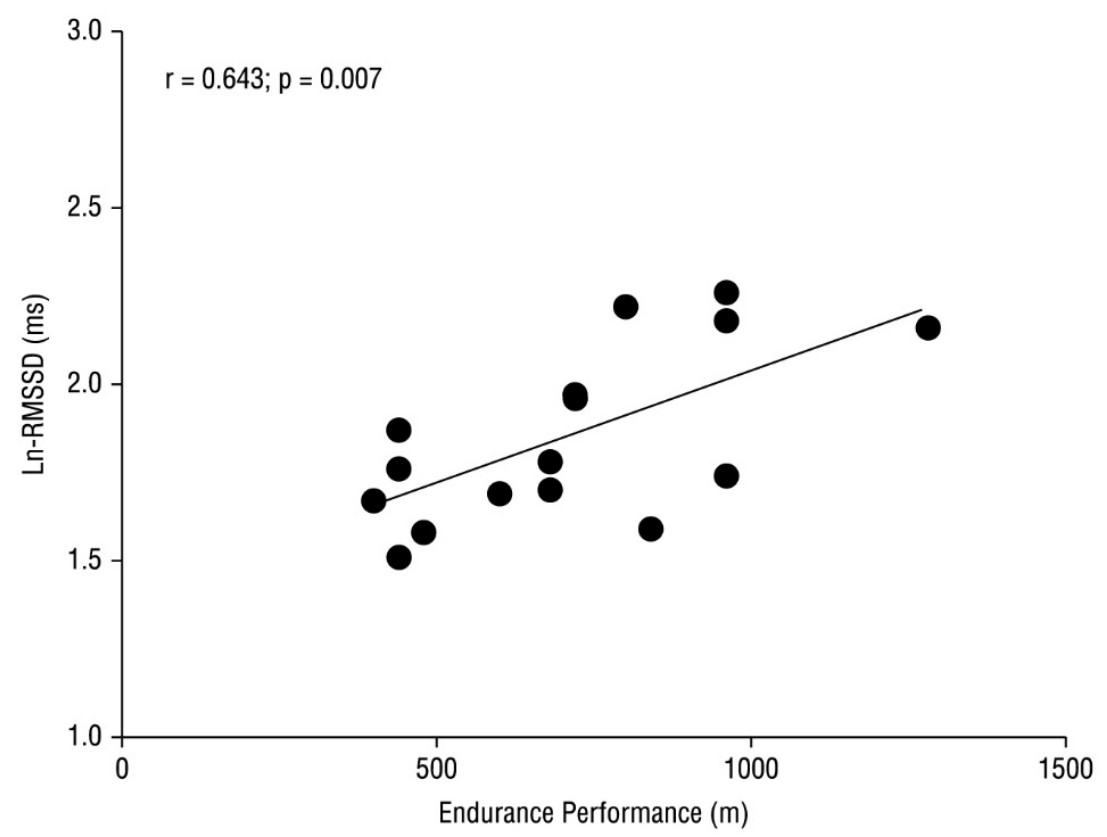

Figure 1. Correlation between the heart rate variability signaled by the vagal index (Ln-RMSSD) and endurance performance in the $Y_{0}-Y_{0}$ test level 1.

The results demonstrated an acceptable relative reliability of HRV resting indices (Ln-RMSSD 1= $4.2 \pm 0.5 \mathrm{~ms}$ vs. Ln-RMSSD 2= $3.9 \pm 0.5 \mathrm{~ms}$;CC $=0.670$; large; $\mathrm{CI}=0.056-0.885)$. However, there was great variation in the inter-subject analysis of the Ln-RMSSD (CV =15.8\%), as well as in the analysis of the mean difference between test and re-test of $0.12 \mathrm{~ms}$ (Figure 2). 


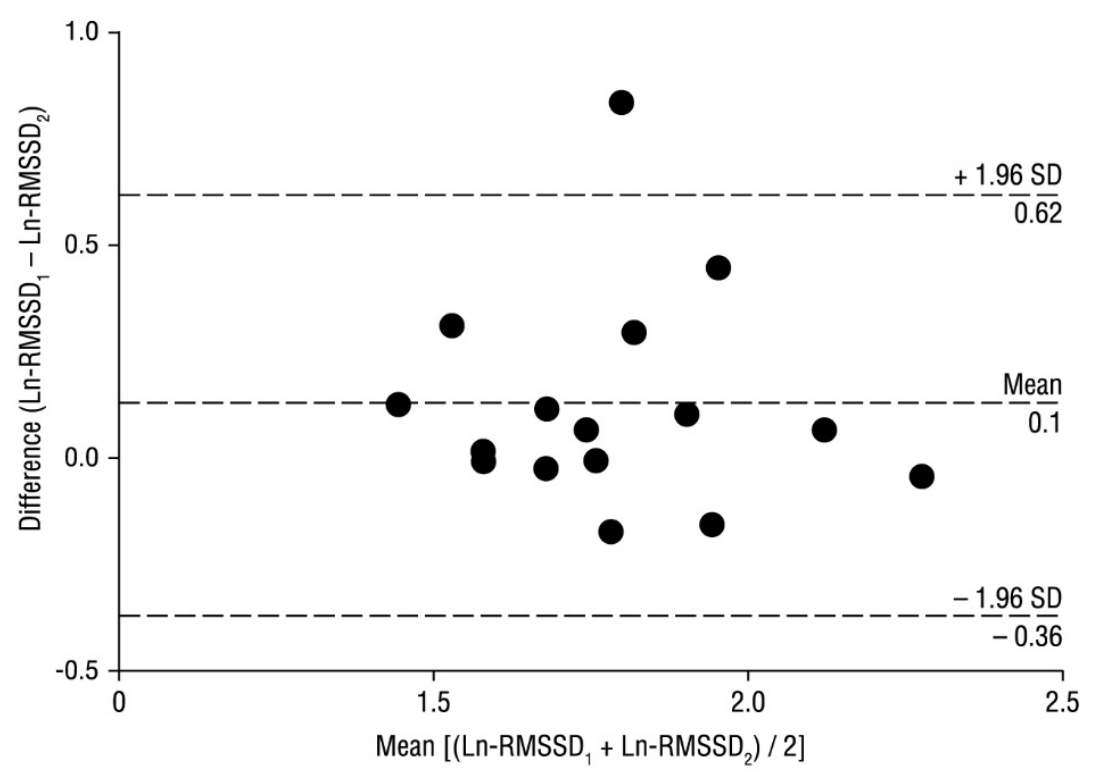

Figure 2. Bland-Altman analysis showing the agreement of the log-transformed root mean square of successive R-R interval differences (Ln-RMSSD) at rest in female futsal players.

\section{DISCUSSION}

The present study analyzed the correlation between the HRV resting measure and endurance performance in female futsal players. Our main finding was a strong correlation between Ln-RMSSD and endurance performance, confirming our initial hypothesis. Moreover, there was an acceptable reproducibility between Ln-RMSSD measures, suggesting a good use in the practical context.

Previous studies reported significant relationships between resting HRV and $\mathrm{VO}_{2 \text { peak }}{ }^{29,30}$ and increased vagal-related $\mathrm{HRV}$ indices are all well-accepted markers of improved aerobic fitness ${ }^{29,30}$. Higher values of Ln-RMSSD during each week of training presented lower perturbation of the cardiac autonomic system $^{6}$, and athletes with lower fitness or higher perceived fatigue demonstrated greater reductions in Ln-RMSSD throughout training ${ }^{11}$. Ln-RMSSD may be used as an indirect measure of the endurance fitness of female futsal players since the results suggested that the players with the lowest endurance performance level presented lower values of the vagal index during two consecutive days in the preseason. This information can be useful when interpreting individual Ln-RMSSD responses throughout training for managing player fatigue.

Specifically, Ln-RMSSD changes were positively correlated with changes in Yo-Yo IR1 performance in professional futsal players ${ }^{5}$. The basal HRV indices may reflect positive changes in parallel to the improvement in Yo-Yo IR1 test performance and high-intensity intermittent activity in futsal players. This concomitant improvement may provide an important and simple monitoring tool for training optimization in futsal and other team sports, avoiding the need for frequent maximal testing. ${ }^{5}$. An increase in Ln-RMSSD should be one of the objectives of the futsal preseason as previous work showed that important physiological adaptations related to performance in specific field tests occur in parallel to the increase in cardiac vagal activity 5 . Chronically 
altered vagal HRV indices with increasing or decreasing trends throughout training have been associated with fatigue and overtraining ${ }^{4,15}$. That a downregulation of the sympathetic nervous system and/or changes in the balance between parasympathetic and sympathetic tone was related to overreaching symptoms ${ }^{14}$. Thus, during training periods individual HRV values and Yo-Yo IR1 performance can be useful in detecting players who do not follow the expected responses of the training routine.

Inclusion of individual $\mathrm{HRV}$ responses is needed to discern how athletes are tolerating training on a personal level ${ }^{10}$, as well as may be useful to detect players deviating from expected responses to training ${ }^{6}$. This may be explained by higher fitness levels conferring more rapid cardiac-parasympathetic recovery following intense training ${ }^{13}$, overall lower homeostatic disturbances from the imposed training load ${ }^{13}$, or a combination of both ${ }^{10}$. High HRV vagal indices at rest are thought to represent a well-recovered state from the previous training sessions and may indicate a preparedness state to cope with subsequent training stimuli ${ }^{18}$.

Resting HRV is an important tool that has been used as an indicator of recovery status in various athletic population $s^{20}$. Our data on resting HRV are useful for individualizing training programmed at the beginning of a futsal preseason because it is possible to identify the athletes that possibly present a good recovery between training days. Thus, the analysis of HRV during the training phases can be important to assess the evolution or involution of the athletes' performance and, thus, make the necessary adjustments to the external training loads ${ }^{18}$. Moreover, the use of the time domain related to the vagal activity is highly reliable and considered adequate for short-term evaluations when compared to HRV spectral indexes ${ }^{3,20}$. The Ln-RMSSD is the most used index of the HRV in studies that involve monitoring in athletes due to its relationship with changes in physical performance, $3,7,20,29,30$, being able to identify a state of fatigue and help in the prevention of non-functional overreaching ${ }^{15,16}$. In environments where athletic performance is sought, athletes constantly strive to adjust external training load, particularly the frequency, duration, and intensity of training. In this perspective, external training loads are adjusted at various times during the training cycle to control fatigue, depending on the training phase ${ }^{12}$.

Among the results of the present study, the ICC presented acceptable reliability. It is important to consider that this index does not have the sensitivity to measure the variability between data, but the ability to detect differences between individuals ${ }^{22,26}$. To assess variability, the typical measurement error (expressed as the $\mathrm{CV}$ ) is the most appropriate measure ${ }^{22}$, with a variation of $15.8 \%$ and $0.12 \mathrm{~ms}$ in the Bland-Altman method. These levels of variability between the two consecutive days of training ( $\mathrm{Ln}-\mathrm{RMSSD} 1=4.2 \pm 0.5 \mathrm{~ms}$ and $\mathrm{Ln}-\mathrm{RMSSD} 2=3.9 \pm 0.5 \mathrm{~ms} ; \mathrm{CV}=15.8 \%$ and Bland Altman $=0.30 \mathrm{~ms}$ ) show a high inter-individual difference, probably due to the effect of a training session between measurements. These data are supported by a meta-analysis, which showed that athletes with a higher training level presented faster parasympathetic reactivation after exercise compared to athletes with a lower training level ${ }^{22}$. Although large $\mathrm{CV}$ s can decrease the signal-to-noise ratio ${ }^{3}$, these findings corroborate a previous study, involving moderately trained men, who presented a CV of $12.3 \%$ when evaluated on four different occasions separated by seven days ${ }^{21}$. Thus, it is possible to assume that the reproducibility of HRV should be further studied in female futsal players, considering a slightly longer time 
interval and a period other than the beginning of pre-season for the players be less susceptible to changes resulting from participation in training sessions during evaluations.

As a practical application, it was shown that the method is reliable to be used as an instrument for the acute monitoring of internal training load during the initial phase of the preseason. These results may help coaches, physical trainers, physiologists, and sports scientists to use the vagal index in training control in female futsal players. Indices vagal of HRV can be useful to monitor the effects of futsal players external training/competitive loads on parasympathetic modulation, being sensitive to both individual characteristics and periods of stress and recovery, and the maintenance and/or increase in HRV seems to be a desirable condition to keep the player able to tolerate training and matches and exhibit optimal performance throughout the season ${ }^{5,18}$.

Some limitations in this study should be considered, such as the data collection of HRV performed on only two days and the lack of comparison with other phases of training, and the lack of other HRV indexes (e.g., SDNN, PNN50). Additionally, in the case of futsal players, we can take as a limitation the fact that we do not control the use of oral contraceptives. Lastly, a sample size calculation was not performed to carry out the research, however, it is known that the sample size is limited within the sports context. So, despite the possible limitation in the generalizability of the present results, the findings of the present research can contribute to sports sciences in scenarios similar to the one studied.

\section{CONCLUSION}

The current study demonstrated a strong positive correlation between LnRMSSD and endurance performance, and despite the acceptable values of intrasubject reliability, HRV at rest presented high inter-individual variability in female futsal players.

\section{COMPLIANCE WITH ETHICAL STANDARDS}

\section{Funding}

This research did not receive any specific grant from funding agencies in the public, commercial, or not-for-profit sectors. This study was funded by the authors.

\section{Ethical approval}

Ethical approval was obtained from the local Human Research Ethics Committee of the University of Fortaleza (UNIFOR), under protocol 1.706.413. The protocol was written according to the standards established by the Declaration of Helsinki.

\section{Conflict of interest statement}

The authors declare that they have no competing interests. 


\section{Author Contributions}

Conceived and designed the experiments: AIF. Performed the experiments: AIF. Analyzed the data:AIF,JCBLP, RMVM. Contributed reagents/materials/ analysis tools: AIF,JCBLP, RMVM, DGSM. Wrote the paper: JCBLP, RMVM, ALM, FYN, LSF, DGSM, AIF.

\section{REFERENCES}

1. Castagna C, D'Ottavio S, Granda Vera J, Barbero Alvarez JC. Match demands of professional futsal: a case study. J Sci Med Sport 2009;12(4):490-4. http://dx.doi. org/10.1016/j.jsams.2008.02.001. PMid:18554983.

2. de Freitas VH, Pereira LA, de Souza EA, Leicht AS, Bertollo M, Nakamura FY. Sensitivity of the Yo-Yo Intermittent Recovery Test and cardiac autonomic responses to training in futsal players. Int J Sports Physiol Perform 2015;10(5):553-8. http://dx.doi.org/10.1123/ ijspp.2014-0365. PMid:25405584.

3. Buchheit M. Monitoring training status with HR measures: do all roads lead to Rome? Front Physiol 2014;5:73. http://dx.doi.org/10.3389/fphys.2014.00073. PMid:24578692.

4. Plews DJ, Laursen PB, Stanley J, Kilding AE, Buchheit M. Training adaptation and heart rate variability in elite endurance athletes: opening the door to effective monitoring. Sports Med 2013;43(9):773-81. http://dx.doi.org/10.1007/s40279-013-0071-8. PMid:23852425.

5. Oliveira R, Leicht A, Bishop D, Barbero-Álvarez J, Nakamura F. Seasonal changes in physical performance and heart rate variability in high level futsal players. Int J Sports Med 2012;34(5):424-30. http://dx.doi.org/10.1055/s-0032-1323720. PMid:23143705.

6. Nakamura FY, Pereira LA, Rabelo FN, Flatt AA, Esco MR, Bertollo M, et al. Monitoring weekly heart rate variability in futsal players during the preseason: the importance of maintaining high vagal activity. J Sports Sci 2016;34(24):2262-8. http://dx.doi.org/10. 1080/02640414.2016.1186282. PMid:27214584.

7. Bellenger CR, Fuller JT, Thomson RL, Davison K, Robertson EY, BuckleyJD. Monitoring athletic training status through autonomic heart rate regulation: a systematic review and meta-analysis. Sports Med 2016;46(10):1461-86. http://dx.doi.org/10.1007/s40279016-0484-2. PMid:26888648.

8. Buchheit M, Gindre C. Cardiac parasympathetic regulation: respective associations with cardiorespiratory fitness and training load. Am J Physiol Heart Circ Physiol 2006;291(1):H451-8. http://dx.doi.org/10.1152/ajpheart.00008.2006. PMid:16501030.

9. Gamelin F, Berthoin S, Sayah H, Libersa C, Bosquet L. Effect of training and detraining on heart rate variability in healthy young men. Int J Sports Med 2007;28(7):564-70. http://dx.doi.org/10.1055/s-2007-964861. PMID: 17373601.

10.Flatt AA, Esco MR, Nakamura FY, Plews DJ. Interpreting daily heart rate variability changes in collegiate female soccer players. J Sports Med Phys Fitness 2017;57(6):90715. PMid:26997322.

11. Kiviniemi AM, Hautala AJ, Kinnunen H, Tulppo MP. Endurance training guided individually by daily heart rate variability measurements. Eur J Appl Physiol 2007;101(6):743-51. http://dx.doi.org/10.1007/s00421-007-0552-2. PMid:17849143.

12.Flatt AA, Esco MR, Nakamura FY. Individual heart rate variability responses to preseason training in high level female soccer players. J Strength Cond Res 2017;31(2):531-8. http:// dx.doi.org/10.1519/JSC.0000000000001482. PMid:27227794.

13.Buchheit M, Chivot A, Parouty J, Mercier D, Al Haddad H, Laursen PB, et al. Monitoring endurance running performance using cardiac parasympathetic function. Eur J Appl Physiol 2010;108(6):1153-67.http://dx.doi.org/10.1007/s00421-009-1317-x. PMid:20033207. 
14.Hedelin R, Bjerle P,Henriksson-Larsen K. Heart rate variability in athletes: relationship with central and peripheral performance. Med Sci Sports Exerc 2001;33(8):1394-8. http://dx.doi.org/10.1097/00005768-200108000-00023. PMid:11474344.

15.Pichot V, Busso T, Roche FDR, Garet M, Costes FDR, Duverney D, et al. Autonomic adaptations to intensive and overload training periods: a laboratory study. Med Sci Sports Exerc 2002;34(10):1660-6. http://dx.doi.org/10.1097/00005768-200210000-00019. PMid:12370569.

16.Plews DJ, Laursen PB, Kilding AE, Buchheit M. Heart rate variability in elite triathletes, is variation in variability the key to effective training? A case comparison. Eur J Appl Physiol 2012;112(11):3729-41.http://dx.doi.org/10.1007/s00421-012-2354-4.PMid:22367011.

17. Oliveira RS, Pedro RE, Milanez VF, Bortolotti H, Vitor-Costa M, Nakamura FY. Relação entre variabilidade da frequência cardíaca e aumento no desempenho físico em jogadores de futebol. Rev Bras Cineantropom Desempenho Hum 2012;14(6):713-22. http://dx.doi.org/10.5007/1980-0037.2012v14n6p713.

18. Nakamura FY, Antunes P, Nunes C, Costa JA, Esco MR, Travassos B. Heart rate variability changes from traditional vs. ultra-short-term recordings in relation to preseason training load and performance in futsal players.J Strength Cond Res 2020;34(10):2974-81. http:// dx.doi.org/10.1519/JSC.0000000000002910. PMid:30601391.

19.Bangsbo J, Iaia FM, Krustrup P. The yo-yo intermittent recovery test: a useful tool for evaluation of physical performance in intermittent sports. Sports Med 2008;38(1):37-51. http://dx.doi.org/10.2165/00007256-200838010-00004. PMid:18081366.

20.Stanley J, Peake JM, Buchheit M. Cardiac parasympathetic reactivation following exercise: implications for training prescription. Sports Med 2013;43(12):1259-77. http://dx.doi. org/10.1007/s40279-013-0083-4. PMid:23912805.

21.Al Haddad H, Laursen P, Chollet D, Ahmaidi S, Buchheit M. Reliability of resting and postexercise heart rate measures. Int J Sports Med 2011;32(8):598-605. http://dx.doi. org/10.1055/s-0031-1275356. PMid:21574126.

22. Hopkins WG. Measures of reliability in sports medicine and science. Sports Med 2000;30(1):1-15. http://dx.doi.org/10.2165/00007256-200030010-00001.PMid:10907753.

23. Young FLS, Leicht AS. Short-term stability of resting heart rate variability: influence of position and gender. Appl Physiol Nutr Metab 2011;36(2):210-8. http://dx.doi. org/10.1139/h10-103. PMid:21609282.

24.Hernando D, Garatachea N, Almeida R, Casajús JA, Bailón R. Validation of heart rate monitor polar RS800 for heart rate variability analysis during exercise. J Strength Cond Res 2018;32(3):716-2.http://dx.doi.org/10.1519/JSC.0000000000001662.PMid:27749728.

25. Task Force of the EuropSean Society of Cardiology and the North American Society of Pacing and Electrophysiology. Heart rate variability: standards of measurement, physiological interpretation and clinical use. Circulation 1996;93(5):1043-65. PMid:8598068.

26.Martin Bland J, Altman DG. Statistical methods for assessing agreement between two methods of clinical measurement. Lancet 1986;327(8476):307-10. http://dx.doi. org/10.1016/S0140-6736(86)90837-8. PMid:2868172.

27.Hopkins WG, Marshall SW, Batterham AM, Hanin J. Progressive statistics for studies in sports medicine and exercise science. Med Sci Sports Exerc 2009;41(1):3-13. http:// dx.doi.org/10.1249/MSS.0b013e31818cb278. PMid:19092709.

28. Hopkins WG. Linear models and effect magnitudes for research, clinical and practical applications. Sportscience 2010;14(1):49-57.

29.Boullosa DA, Nakamura FY, Perandini LA, Leicht AS. Autonomic correlates of Yo-Yo performance in soccer referees. Mot Rev Educ Física 2012;18(2):291-7. http://dx.doi. org/10.1590/S1980-65742012000200009.

30.Buchheit M, Simpson MB, Al Haddad H, Bourdon PC, Mendez-Villanueva A. Monitoring changes in physical performance with heart rate measures in young soccer players. Eur 
J Appl Physiol 2012;112(2):711-23. http://dx.doi.org/10.1007/s00421-011-2014-0. PMid:21656232. 